11. Yeung, A. W. K., Identification of seminal works that built the foundation for functional magnetic resonance imaging studies of taste and food. Curr. Sci., 2017, 113, 1225-1227.

12. Kim, E. S., Yoon, D. Y., Kim, H. J., Jeon, H. J., Lee, J. Y., Cho, B.-M. and Lee, K., Citation classics in neurointerventional research: a bibliometric analysis of the 100 most cited articles. J. Neurointerv. Surg., 2017, 9, 508-511.

13. Yeung, A. W. K., Sex differences in brain responses to food stimuli: a meta-analysis on neuroimaging studies. Obes. Rev., 2018, 19, 1110-1115.

14. van der Laan, L. N., De Ridder, D. T., Viergever, M. A. and Smeets, P. A., The first taste is always with the eyes: a metaanalysis on the neural correlates of processing visual food cues. Neuroimage, 2011, 55, 296-303.

15. Yeung, A. W. K., Goto, T. K. and Leung, W. K., Basic taste processing recruits bilateral anteroventral and middle dorsal insulae: an activation likelihood estimation meta-analysis of fMRI studies. Brain Behav., 2017, 7, e00655.

16. van Meer, F., van der Laan, L. N., Adan, R. A., Viergever, M. A. and Smeets, P. A., What you see is what you eat: an ALE metaanalysis of the neural correlates of food viewing in children and adolescents. Neuroimage, 2015, 104, 35-43.

17. Yeung, A. W. K., Goto, T. K. and Leung, W. K., Affective value, intensity and quality of liquid tastants/food discernment in the human brain: an activation likelihood estimation meta-analysis. Neuroimage, 2018, 169, 189-199.

18. Makel, M. C. and Plucker, J. A., Facts are more important than novelty: replication in the education sciences. Educ. Res., 2014, 43, 304-316.

19. Makel, M. C., Plucker, J. A., Freeman, J., Lombardi, A., Simonsen, B. and Coyne, M., Replication of special education research: Necessary but far too rare. Rem. Spec. Educ., 2016, 37, 205-212.

20. Makel, M. C., Plucker, J. A. and Hegarty, B., Replications in psychology research: how often do they really occur? Perspect. Psychol. Sci., 2012, 7, 537-542.

21. Pridemore, W. A., Makel, M. C. and Plucker, J. A., Replication in criminology and the social sciences. Annu. Rev. Criminol., 2018, 1, 19-38.

22. Chambers, C. D., Registered reports: a new publishing initiative at Cortex. Cortex, 2013, 49, 609-610.

23. Poldrack, R. A. et al., Scanning the horizon: towards transparent and reproducible neuroimaging research. Nat. Rev. Neurosci., 2017, 18, 115-126.

24. Yeung, A. W. K., Do neuroscience journals accept replications? a survey of literature. Front. Hum. Neurosci., 2017, 11, 468.

25. Cook, B. G., Collins, L. W., Cook, S. C. and Cook, L., A replication by any other name: a systematic review of replicative intervention studies. Rem. Spec. Educ., 2016, 37, 223-234.

Received 31 October 2018; revised accepted 30 May 2019

doi: $10.18520 / \mathrm{cs} / \mathrm{v} 117 / \mathrm{i} 8 / 1345-1347$

\section{Use of a weather forecast model to identify suitable sites for new wind power plants in Karnataka}

\author{
Anasuya Gangopadhyay ${ }^{1, *}$, Radhika Kanase ${ }^{2}$, \\ Greeshma Mohan ${ }^{2}$, Madhuparna Halder ${ }^{2}$, \\ Medha Deshpande ${ }^{2}$, Parthasharathi \\ Mukhopadhyay $^{2}$ and J. Srinivasan ${ }^{1}$
}

${ }^{1}$ Divecha Centre for Climate Change, Indian Institute of Science, Bengaluru 560 012, India

${ }^{2}$ Indian Institute of Tropical Meteorology, Dr Homi Bhabha Road, Pune 411 008, India

The wind speed forecast by a weather forecast model (with a resolution of $3 \mathrm{~km}$ ) has been used to identify regions with high wind speed in Karnataka. The correlation between daily wind speed predicted by the model and the measured wind speed at three stations in Karnataka has been shown to be high. Based on this model, new locations have been suggested for the installation of new wind power plants in Karnataka.

Keywords: Karnataka, potential site, renewables, weather model, wind plant.

THE installed capacity of wind power plants in India is expected to reach 60 Gigawatts (GW) by 2022 . Karnataka is expected to attain an installed capacity of $6.2 \mathrm{GW}$ (ref. 1). At the end of June 2018, the total installed wind capacity of Karnataka was $4.7 \mathrm{GW}$ (ref. 2). In order to identify the regions suitable for the location of the new wind power plants, grid stability and environmental impact need to be considered. The majority of the wind power plants in Karnataka are owned by independent power producers (IPPs). The locations of wind power plants where the average wind speed is higher compared to other places would mean more energy generation. Hence, locating high wind speed regions of the state is important. Some of the areas with high-wind in Karnataka have many wind power plants and hence may not be suitable for new power plants. So, it is a critical task to identify areas where the wind speed is reasonably high and there is a possibility of installation of new wind power plants. Wind speed varies dramatically over small distances due to local orography. We do not have sufficient number of stations with wind data to identify the areas suitable for new wind power plants. Wind is intermittent by nature and fluctuates in time scales from seconds up to a season. The increasing share of wind energy in the energy mix of the state will pose a new challenge for grid stability. The variability of wind energy decreases when energy is fed to the grid from geographically distributed wind power plants. This is called geographic smoothing ${ }^{3}$. In Karnataka,

*For correspondence. (e-mail: anasuyagangopadhyay@gmail.com) 

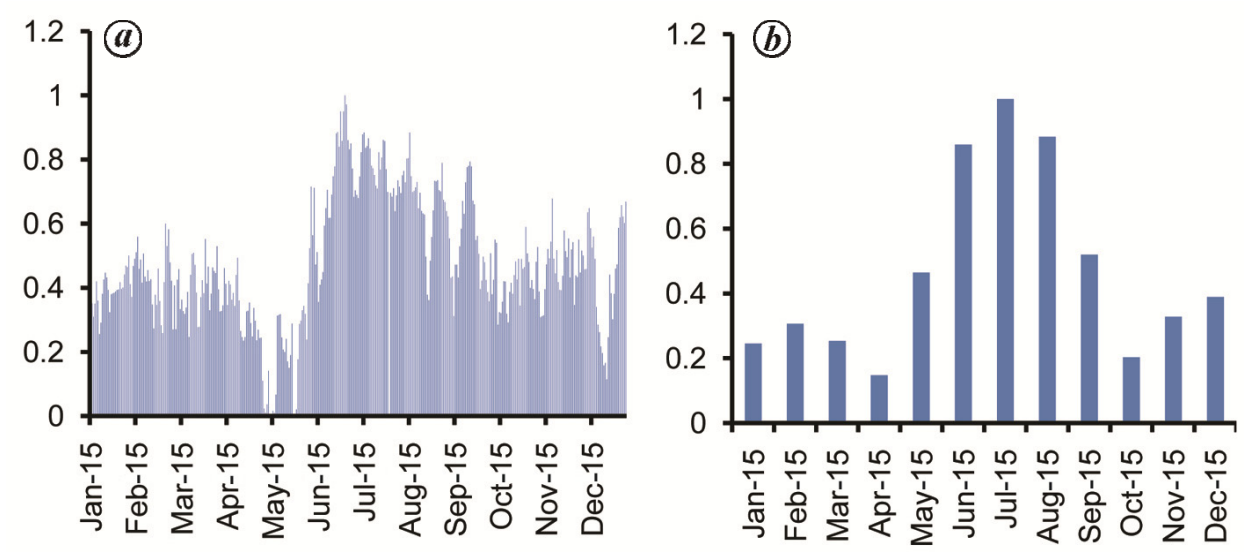

Figure 1. $\boldsymbol{a}$, Daily average wind speed at Haikal weather monitoring station in 2015; $\boldsymbol{b}$, Normalized monthly average wind power generation from a wind plant near Chitradurga in 2015.

there are four major types of variation in wind energy. They are interannual, seasonal, diurnal and minute to minute. The wind energy generation is higher during the monsoon months compared to other seasons. There can be variation is average monsoon wind speed depending on the strength of the monsoon. The diurnal cycle of winds is different at different locations. Hence, the power generated from plants located in different regions may result in a geographical or spatial smoothing of the diurnal cycle. The spatial smoothing can play a role in decreasing the volatility of wind generation and help in achieving grid stability ${ }^{4}$. The National Institute of Wind Energy (NIWE) in Chennai has used a meso-micro model to identify regions suitable for wind power plants in India ${ }^{5}$. The details of this model and their validation are not available.

In this study, we have utilized a monsoon forecast model made by Indian Institute of Tropical Meteorology, Pune using weather research and forecasting (WRF) model for identifying regions with high wind speed for various locations in Karnataka. This analysis can help in identifying new locations for wind power plants in Karnataka.

To identify the possible high wind areas, we need to understand the wind pattern of the state. It is evident from the recorded data that the regions with high wind speed do not vary much from year to year. Hence, identification of wind zones for a particular year will help us to compare different areas and recommend suitable high wind regions for the installation of new wind power plants. There are two different ways to understand the wind pattern in the state. The first is with the help of recorded data from different weather monitoring stations across Karnataka. The second is by using a weather forecast model. Karnataka has a total of 72 weather monitoring stations. Data is not available continuously for all the stations. Every monitoring station has recorded wind data for a certain time period. Presently, wind data is being recorded at 14 stations throughout Karnataka ${ }^{6}$. Wind speed at these stations is measured at different heights like $100,80,50,25$ and $10 \mathrm{~m}$ above ground level. The measurement data is available at WRA portal of NIWE. We have used wind speed at $80 \mathrm{~m}$ above ground level for this study.

Wind speed is spatially variable and difference of a few kilometres can cause a large variation in wind speed due to local topography. Hence the data from a few stations are not sufficient to map the locations suitable for the location of new wind power plants. A weather forecast model with high resolution can provide data at a reasonable resolution. The measured wind data can be used to validate model predictions. Figure $1 a$ shows daily average wind speed for Haikal weather monitoring station for 2015. It can be seen that the wind speed is reasonably higher during monsoon (June, July, August and September; JJAS) compared to other months at Haikal. Figure $1 b$ shows the normalized monthly average wind power generation from a wind plant near Chitradurga. The difference in generation between non-monsoon and monsoon month is evident in Figure $1 b$. The difference is more prominent in the case of generation (Figure $1 b$ ) compared to wind speed (Figure $1 a$ ). This occurs due to the nonlinear relationship between wind speed and power generation for very low wind speed. Although theoretically, the power generation from a windmill is proportional to the cube of wind speed, in reality, power generation from a windmill follows the power curve provided by the manufacturer. The windmill starts generating when the wind speed is more than the cut-in speed ( 3 to $4 \mathrm{~m} / \mathrm{s}$ ) and increases depending on the efficiency of the particular windmill until the wind speed reaches the rated speed $(12$ or $13 \mathrm{~m} / \mathrm{s})$. The windmills stop generating when the wind speed is beyond cut-off speed (20 or $25 \mathrm{~m} / \mathrm{s}$ ). The similar seasonal trend of wind speed can be observed throughout Karnataka. As the wind speed is high in Karnataka during the monsoon (JJAS), we have 
used the wind speed forecast for this period for the analysis. The measured wind speed data for the same time period are available for three stations (Haikal, Kanchikere and Gunduthanda) and have been used for validation of the model. After validation, the model is used to identify high wind regions in Karnataka. These regions are considered suitable for the installation of new wind power plants. The methodology is shown in Figure 2.

Indian Institute of Tropical Meteorology (IITM), Pune has developed a model with a $3 \mathrm{~km}$ spatial resolution to predict the wind speed at various levels over Karnataka. Mukhopadhyay et $a l^{7}$ have used a WRF-based model to forecast wind speed for certain locations in Maharashtra. Their results show that this approach was promising. The bias-corrected model gave a more accurate forecast and the correlation coefficient of the predicted wind and measured wind at a location, Agaswadi was around 0.9

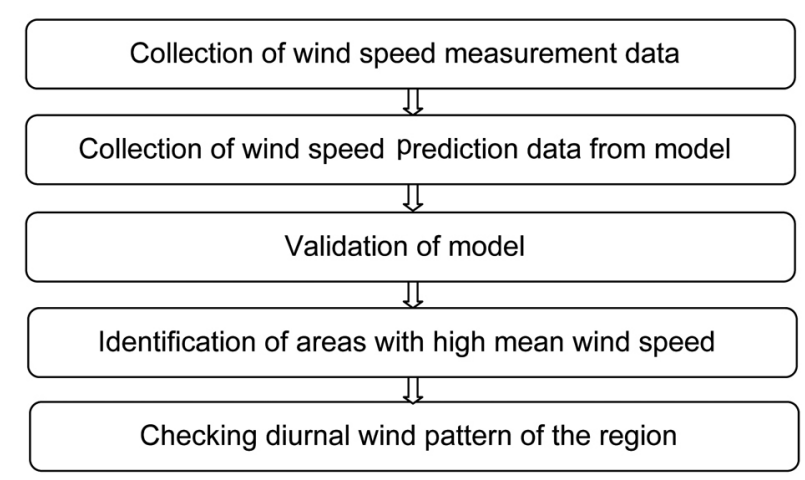

Figure 2. Methodology used to identify suitable sites for new wind power plants.

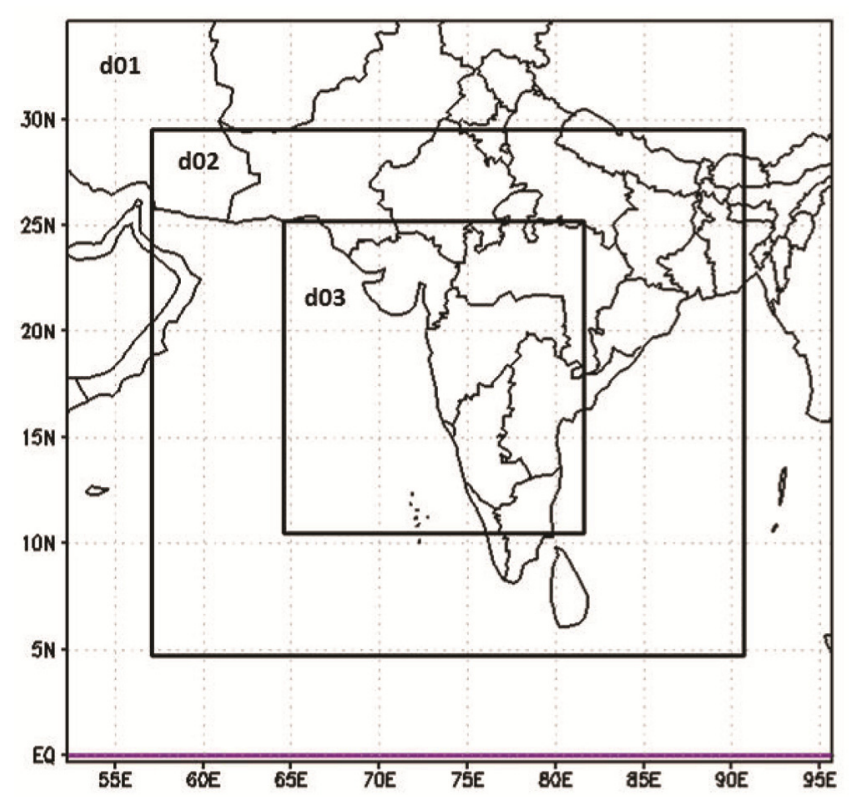

Figure 3. Weather research and forecasting domain configuration. Parent domain is at $27 \mathrm{~km}$ and nested are at 9 and $3 \mathrm{~km}$ horizontal resolution. (ref. 7). We have obtained wind speed forecast covering Karnataka region at a resolution of $3 \mathrm{~km}$ for JJAS for 2016 from IITM. WRF version 3.7.1 (ref. 8) is used for generating wind forecast. The model is run in three domains with $27,9,3 \mathrm{~km}$ as horizontal resolution (Figure $3)$. Different sensitivity experiments are conducted to generate a day-ahead forecast for JJAS 2016 over Karnataka region. These experiments are summarized in Table 1 and the sequence of experiments is explained in Figure 4. Experiments started with GFS analysis initial condition of $0.5^{\circ} \times 0.5^{\circ}$ resolution with a random combination of different physics parameterization options. The model showed very less skill in forecasting the daily evolution of hub height winds with correlation coefficient $r=0.3$. In order to further improve the skill of model, microphysics (MP) and cumulus parameterization (CP) sensitivity experiments are conducted simultaneously. Morrison microphysics and Kain-Fritsch (KF) cumulus scheme's performance was satisfactory and this configuration is fixed for further sensitivity experiments of planetary boundary layer (PBL) schemes. Yonsei University scheme (YSU), being better among other PBL schemes, is used for initial and boundary condition data sensitivity experiments. GFST1534 ( 12.5 km, Global Forecast System now run by IMD) as initial and boundary conditions gave better results and the same is used to carry out the vertical level sensitivity experiments. Proper representation

Table 1. Different sensitivity experiments conducted to generate a day ahead forecast over Karnataka region

\begin{tabular}{|c|c|}
\hline $\begin{array}{l}\text { Initial condition } \\
\text { sensitivity }\end{array}$ & $\begin{array}{l}\text { GFS analysis }\left(0.5^{\circ} \times 0.5^{\circ}\right) \\
\text { GFS forecast }\left(0.25^{\circ} \times 0.25^{\circ}\right) \\
\text { GFST1534 forecast }\left(\mathbf{0 . 1 2 5}^{\circ} \times \mathbf{0 . 1 2 5}^{\circ}\right)\end{array}$ \\
\hline $\begin{array}{l}\text { Planetary boundary } \\
\text { layer scheme }\end{array}$ & $\begin{array}{l}\text { Yonsei University (YSU) } \\
\text { Mellor-Yamada-Janjic (MYJ) } \\
\text { Quasi-normal scale elimination (QNSE) } \\
\text { Mellor-Yamada-Nakanishi and Niino } \\
\text { Level 2.5 (MYNN2.5) } \\
\text { MYNN3 scheme } \\
\text { Bougeault-Lacarrere (BouLac) } \\
\text { University of Washington (UW) PBL } \\
\quad \text { scheme } \\
\text { Total energy mass flux (TEMF) } \\
\text { Shin Hong scale aware scheme } \\
\text { MRF }\end{array}$ \\
\hline Microphysics sensitivity & $\begin{array}{l}\text { Morrison } \\
\text { Thompson } \\
\text { WDM6 }\end{array}$ \\
\hline Cumulus sensitivity & $\begin{array}{l}\text { Kain Fritsch (KF) } \\
\text { Betts-Miller-Janjic (BMJ) } \\
\text { Grell-Freitas Ensemble (GF) }\end{array}$ \\
\hline No. of vertical levels & $\begin{array}{l}31 \\
45 \\
52\end{array}$ \\
\hline $\mathrm{LU} / \mathrm{LC}$ data & $\begin{array}{l}\text { USGS } \\
\text { MODIS } \\
\text { NRSC }\end{array}$ \\
\hline
\end{tabular}

Bold letters indicate the final chosen configuration from different experiments. 


\section{RESEARCH COMMUNICATIONS}

of land use and land cover (LU/LC) is also important for improving the model skill. Finally, 45 vertical levels and best combination (Morrison-KF-YSU-GFST1534) an used for LU/LC sensitivity. Thus MODIS and NRSC LU/LC give similar results. So for generating a day ahead forecast over Karnataka region for whole monsoon season of 2016, in addition to 45 vertical levels, we used MODIS LU/LC along with different physical parameterizations such Morrison as Microphysics and YSU as PBL scheme. The cumulus convection is explicitly resolved in the innermost domain, whereas for outer domains KF as cumulus scheme is used to resolve the convection (Figure 4). The model is initialized with the 00UTC GFST1534. The boundary conditions are updated every 3 hours with GFST1534 forecast fields and output is saved at $30 \mathrm{~min}$ interval. Rapid and accurate radiative transfer model (RRTM) (longwave) and Dhudhia (shortwave) schemes are used for radiation ${ }^{7}$.

We have used data from different sources, for the validation of the model forecast: (a) wind power plant locations (latitude and longitude) are identified based on Google map and Commissioning Status document for wind plants shared by Karnataka Renewable Energy Development Ltd. (b) Wind data for validation of the model was collected from NIWE for various weather stations from WRA portal.

The model output is available at 45 different levels above ground. Out of these levels, four levels (50, 70, 90, 110) are below $150 \mathrm{~m}$. We have used linear interpolation based on model output at 70 and $90 \mathrm{~m}$ height to calculate the predicted wind speed at $80 \mathrm{~m}$ above ground level. We

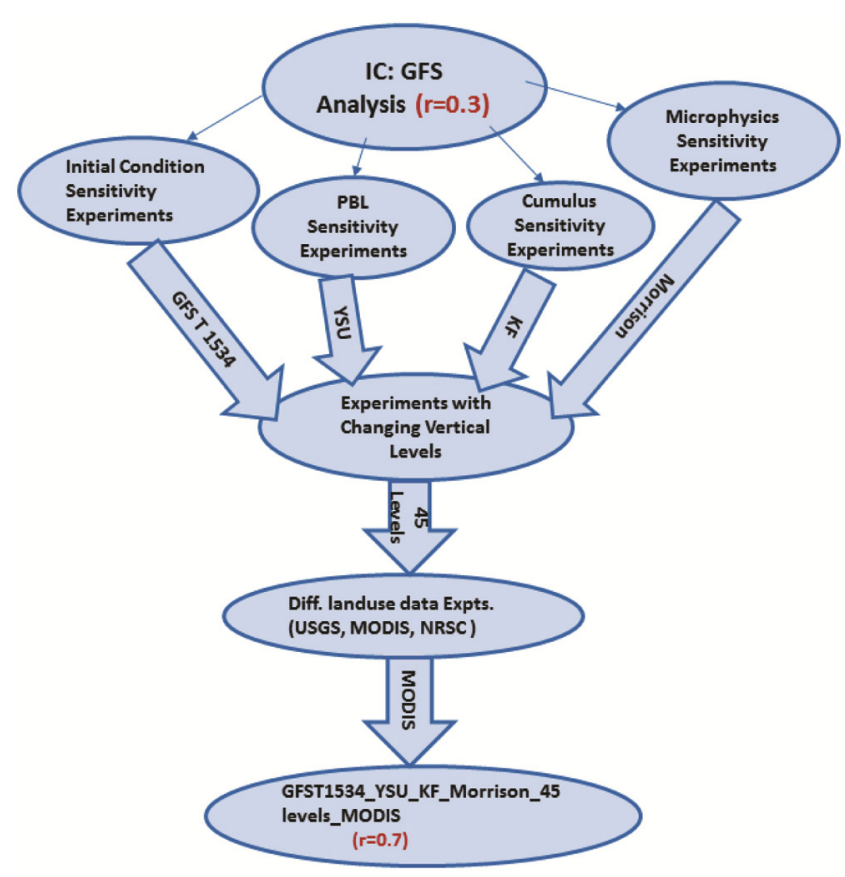

Figure 4. Flow chart of different sensitivity experiments conducted for obtaining best model configuration. start validation of the model, using the observed data for Haikal, Gunduthanda and Kanchikere at $80 \mathrm{~m}$ above ground. To validate the model, we have compared the measured and predicted wind speed, compared the wind speed distribution and calculated the correlation between measured and predicted daily average wind speed and the diurnal cycle.

To study the deviations of prediction we calculated the difference between actual and predicted wind speed for every half hour in a particular location. We define the difference between the actual and predicted wind speed at a certain time as delta (eq. (1)).

$$
\begin{aligned}
\operatorname{Delta}(\mathrm{m} / \mathrm{s})= & \text { predicted wind speed }(\mathrm{m} / \mathrm{s})-\text { actual } \\
& \text { wind speed }(\mathrm{m} / \mathrm{s}) .
\end{aligned}
$$

Mean delta values for a particular month for a specific location are used for bias correction. Bias correction was done for all the three stations and the percentage errors in the mean wind speed prediction reduced substantially for all three stations. The formula used for bias correction is given in eq. (2). Table 2 shows monthly mean wind bias values (delta values) for all three stations. Predicted wind speeds in all three stations show a positive bias. After bias correction, the root mean square error (RMSE) of prediction for daily wind speed at Haikal, Gunduthanda and Kanchikere was $12 \%, 9 \%$ and $14 \%$ respectively for July 2016.
Bias corrected wind speed $(\mathrm{m} / \mathrm{s})=$ predicted wind speed - monthly mean delta.

Figures $5 a$ and $b$ shows the wind speed probability density functions (PDFs) for Haikal and Gunduthanda July and August 2016 after bias correction. The PDFs of measured and predicted values match reasonably well for both the places. In the next step, we compared the measured and predicted daily average wind speed from June to September 2016. Table 3 shows the monthly correlation coefficients for three weather monitoring stations. Figure

Table 2. Monthly mean wind bias

\begin{tabular}{lcccc}
\hline Monthly mean delta & June & July & August & September \\
\hline Haikal & 2.55 & 2.18 & 1.5 & 0.71 \\
Gunduthanda & 1.30 & 1.83 & 1.05 & NA \\
Kanchikere & 1.27 & 2.23 & 2.04 & 1.34 \\
\hline
\end{tabular}

Table 3. Correlation coefficients (predicted versus measured) for daily wind speed

\begin{tabular}{lcccc}
\hline & June & July & August & September \\
\hline Haikal & 0.79 & 0.95 & 0.92 & 0.54 \\
Gunduthanda & 0.87 & 0.97 & 0.88 & NA \\
Kanchikere & 0.85 & 0.94 & 0.93 & 0.68 \\
\hline
\end{tabular}



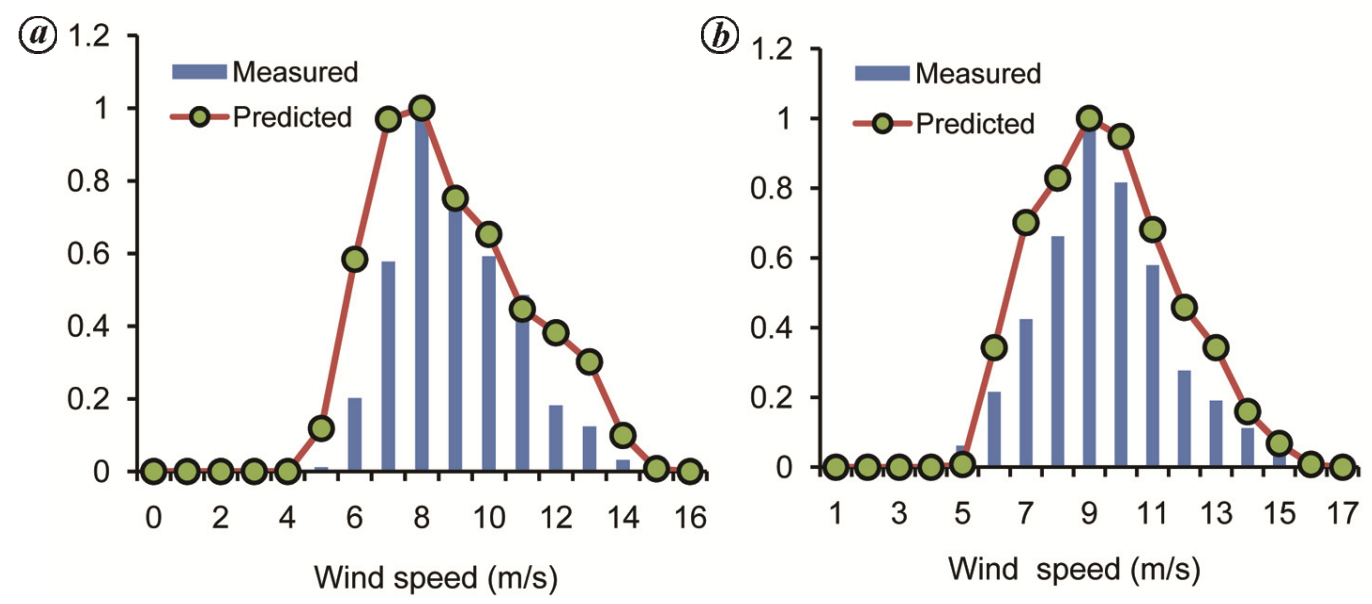

Figure 5. Probability density function of wind speed at (a) Haikal and (b) Gunduthanda during August 2016.
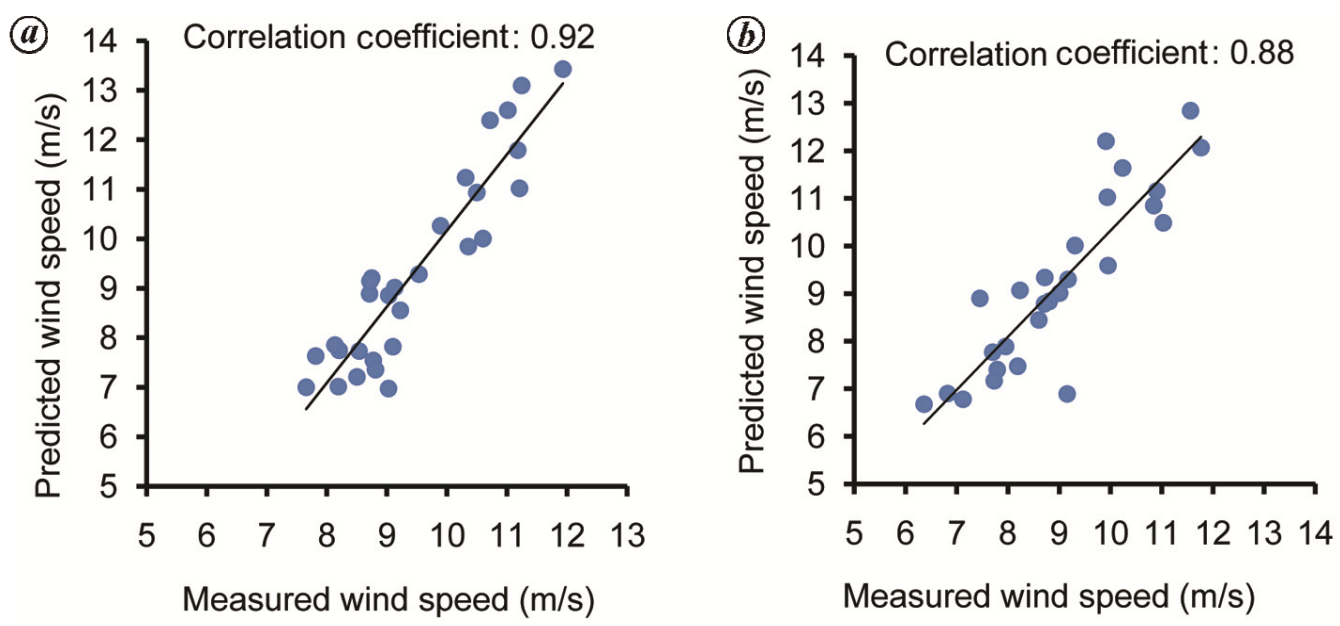

Figure 6. Correlation between measured and predicted wind speed at (a) Haikal and (b) Gunduthanda during August 2016.

$6 a$ and $b$ shows a considerable amount of correlation for Haikal (0.92) and Gunduthanda (0.88) weather stations for August 2016. Table 4 lists the correlation coefficients for the monthly average diurnal cycle of three weather monitoring stations for peak monsoon months (July and August). It can be seen from Table 4 that, the model has considerable accuracy in predicting the monthly average diurnal profile of wind speed for July and August 2016. Figure $7 a$ and $b$ shows the average diurnal cycle of wind speed at Haikal (August 2016) and Kanchikere (July 2016).

After validation, we have used the predicted mean wind speed to identify high wind areas with potential for installation of new wind power plants in Karnataka. The wind speed in a region varies with the local topography. In Karnataka, the highest wind speed zones are located near areas with elevation above $600 \mathrm{~m}$. The mean wind speed for Karnataka in July 2016 in the model was $8.4 \mathrm{~m} / \mathrm{s}$ (at the height of $70 \mathrm{~m}$ above ground). In some places, the average wind speed was higher than $8.44 \mathrm{~m} / \mathrm{s}$. These places are suitable for installation of wind plants. Most of the existing wind power plants in Karnataka are located in regions with wind speeds in the range $12-13 \mathrm{~m} / \mathrm{s}$. The cut-in speed (i.e. the speed at which the wind turbine starts producing electricity) is in the range of $3-4 \mathrm{~m} / \mathrm{s}$. The wind turbine stops working at very high wind speed $(20-25 \mathrm{~m} / \mathrm{s})$ which is known as cut-out speed. Most of the turbines achieve their rated power output at a wind speed of $12 \mathrm{~m} / \mathrm{s}$. However, there are very few places in Karnataka having average wind speed of $12 \mathrm{~m} / \mathrm{s}$ in July. In this study, we have considered areas having average wind speed above $10 \mathrm{~m} / \mathrm{s}$ during July as suitable for future wind power plants. At $10 \mathrm{~m} / \mathrm{s}$ wind speed, a NEG Micon NM 82/1650 wind turbine can generate approximately $75 \%$ of its rated generation ${ }^{9}$. Areas having average wind speed larger than $10 \mathrm{~m} / \mathrm{s}$ at the height of $80 \mathrm{~m}$ above ground in July 2016 are shaded in green in Figure 8. The political map of Karnataka is shown by a red line. The 


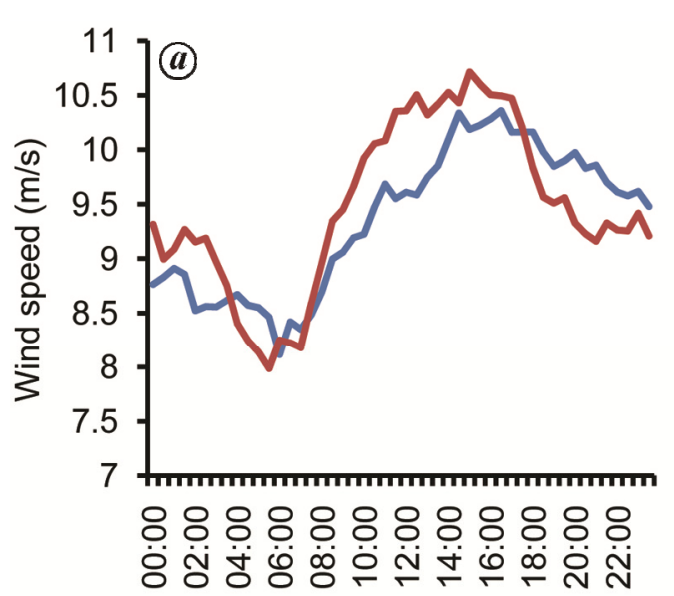

-Predicted -Measured

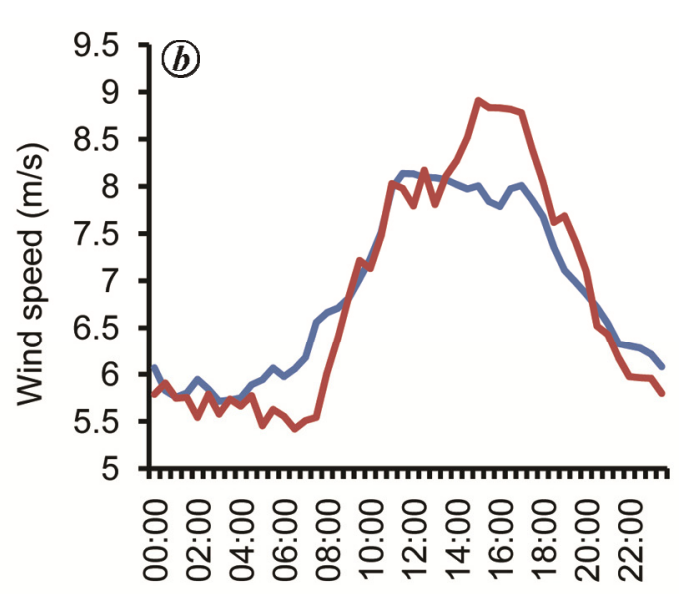

-Predicted Measured

Figure 7. Average diurnal cycle of wind speed at (a) Haikal and (b) Kanchikere (July 2016).

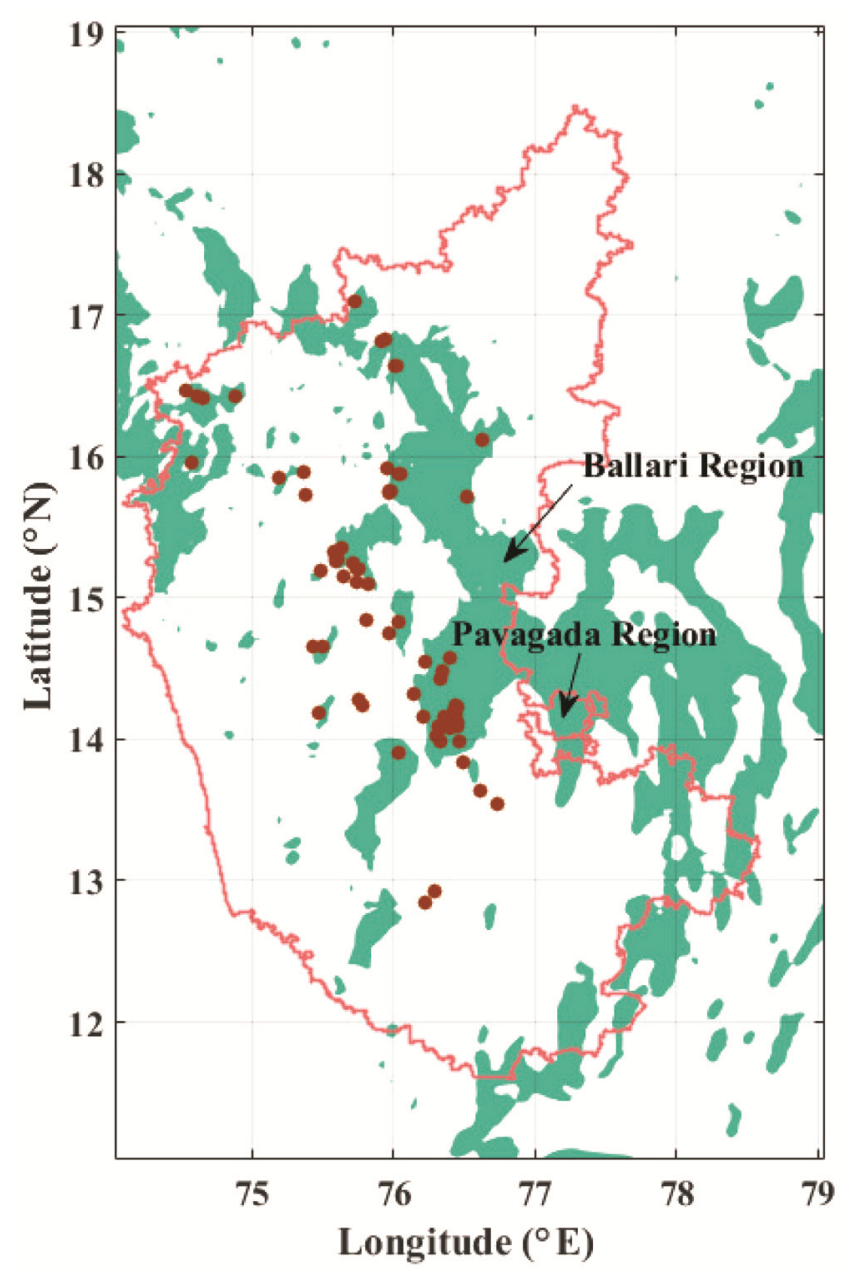

Figure 8. Areas with mean wind speed more than $10 \mathrm{~m} / \mathrm{s}$ at $80 \mathrm{~m}$ above ground level in July 2016 and location of existing wind plants in Karnataka.

brown dots show the present location of wind power plants in Karnataka. Some of the existing plants are located in areas where mean wind speed in July is less than $10 \mathrm{~m} / \mathrm{s}$. However, a few areas with high wind speed do not have wind power plants. A few of these regions are Ballari region and Pavagada region (denoted withblack circles). As many mines are located in the Ballari region and solar parks are coming up at Pavagada, the transport facility and grid connectivity are expected to be good in the area. High wind zones are also available near Baba Budangiri in Chikmagalur and BR Hills which are covered with forest ${ }^{10}$. Installing wind plants in these regions would harm the local biodiversity. The Bellary region has a different diurnal pattern compared to most of the other wind plants in Karnataka. Therefore, the installation of new wind power plants in this region may bring in geographical smoothing in the diurnal cycle and help in stabilizing the grid. Assuming that an average of $9 \mathrm{MW}$ of wind power can be installed per square kilometre area $^{11}$, approximately less than $20 \%$ of the identified area would be sufficient for installation of new wind power plants required to meet the 2022 target of Karnataka.

In view of the ambitious wind energy generation target of Karnataka, it is critical to find areas suitable for the installation of new wind power plants. Understanding the wind pattern and its relation to the local topography is important in this aspect. A numerical weather prediction model helps in simulating the wind pattern of the state at a high resolution.

In this study, we have used the output of the weather forecast model used by IITM, Pune. We have first validated the model with the measured wind speed at various wind monitoring stations. The present and past measurements of wind speed were used in validation of the model. The probability density function, daily average wind speed and diurnal cycle were used as criteria for validation. It is evident that the model could capture the wind pattern of the region with reasonable accuracy level. Hence, the model is useful in identifying areas with relatively high mean wind speed. 


\section{RESEARCH COMMUNICATIONS}

Table 4. Correlation coefficients for the monthly average diurnal cycle

\begin{tabular}{lcc}
\hline & July & August \\
\hline Haikal & 0.75 & 0.82 \\
Gunduthanda & 0.70 & 0.78 \\
Kanchikere & 0.94 & 0.95 \\
\hline
\end{tabular}

We have used the predicted mean wind speed from the model to identify high wind areas with potential for installation of new wind power plants in Karnataka. In Karnataka, the highest wind speed zones are located near areas with elevation above of $600 \mathrm{~m}$. According to the model, the mean wind speed for Karnataka in July 2016 was $8.4 \mathrm{~m} / \mathrm{s}$. At a few places, the average wind speed is higher than $8.4 \mathrm{~m} / \mathrm{s}$. Those places are suitable for installation of wind plants. At $10 \mathrm{~m} / \mathrm{s}$ wind speed a NEG Micon NM 82/1650 wind turbine can generate approximately $75 \%$ of its rated generation ${ }^{9}$.

Most of the wind plants of Karnataka are located at a height of $600 \mathrm{~m}$ amsl or more. Some of the existing plants are located in areas where mean wind speed in July is less than $10 \mathrm{~m} / \mathrm{s}$. However, a few areas with high wind speed do not have wind power plants. One of these regions is Bellary Mines. As many mines are located in the region, the transport facility is available in the area. This makes the region more suitable for the installation of new wind plants. Interestingly, this region has a different diurnal pattern compared to most of the other regions in Karnataka. Therefore, the installation of new wind plants in this region may bring in geographical smoothing in the diurnal cycle level and help in grid management too. High wind zones are also available near Baba Budangiri in Chikmagalur and BR Hills which are covered with forest ${ }^{10}$. Installing wind plants in these regions would harm the local biodiversity. Hence, Ballari and Pavagada regions are recommended for the installation of new wind plants.

1. Ministry of New and Renewable Energy, Tentative state-wise break-up of renewable power target to be achieved by the year 2022 so that cumulative achievement is $1,75,000 \mathrm{MW}$; https://mnre.gov.in/file-manager/UserFiles/Tentative-State-wisebreak-up-of-Renewable-Power-by-2022.pdf (accessed on 24 July 2018).

2. Karnataka Renewable Energy Development Ltd, RE progress report up to June 2018; http://kredlinfo.in/ (accessed on 24 July 2018).

3. Bandi, M. M., Spectrum of wind power fluctuations. Phys. Rev. Lett., 2017, 118, 028301.

4. Gangopadhyay, A. and Srinivasan, J., Impact of spatial variation of wind generation in India. In 1st International Conference on Large-Scale Grid Integration of Renewable Energy in India, New Delhi, 2017; http://regridintegrationindia.org/wp-content/uploads/ sites/3/2017/09/GIZ17 096 posterpaper_Anasuya_Gangopadhyay. pdf (accessed on 24 July 2018)
5. National Institute of Wind Energy, Ministry of New and Renewable Energy, Government of India, Wind power potential at $100 \mathrm{~m} \mathrm{agl}$ h http://niwe.res.in/department_wra_100m\%20agl.php (accessed on 9 Auguat 2018).

6. Ministry of New and Renewable Energy, List of wind monitoring stations with maws and Mawpd (MNRE as on 28.02.15), 2015; http://niwe.res.in/NIWE_OLD/Docu/List_of_WMS_on_28.02.2015. pdf (accessed on 24 July 2018).

7. Mukhopadhyay, P., Despande, M., Kanase, R., Mukherjee, M., Mohan, G. and Ganai, M., Recent initiative of solar and wind forecasting using a high resolutioncloud resolving model. In 1st International Conference on Large-Scale Grid Integration of Renewable Energy in India, New Delhi, 2017; http:// regridintegrationindia.org/wp-content/uploads/sites/3/2017/09/6B 3_GIZ17_063_paper_PMukhopadhyay_170816.pdf (accessed on 24 July 2018).

8. Skamarock, W. C. et al., A description of the advanced research WRF version 3, NCAR Tech. Note NCAR/TN-4751 STR, 2008, pp. 1-113; http://www.mmm.ucar.edu/wrf/users/docs/arw_v3_bw.pdf

9. NEG Micon NM 82/1650, Power curve and technical details; https://en.wind-turbine-models.com/turbines/1149-neg-micon-nm82-1650 (accessed on 24 July 2018).

10. Athreya, V. et al., Spotted in the news: using media reports to examine leopard distribution, depredation, and management practices outside protected areas in Southern India. PLOS ONE, 2015, 10(11), e0142647; https://doi.org/10.1371/journal.pone.0142647 (accessed on 24 July 2018).

11. Ministry of New and Renewable Energy, Frequently asked questions on wind power programme (FAQ); https://mnre.gov.in/filemanager/UserFiles/faq wind.pdf (accessed on 23 July 2018).

ACKNOWLEDGEMENTS. We thank National Institute of Wind Energy for sharing wind speed measurement data (WRA Portal) for various measurement stations that have been used for validation of the model. We also thank Mr S. B. Chandrashekharaiah (State Load Dispatch Centre, Karnataka) for providing wind power generation data for the study. We gratefully acknowledge the support at the data collection stage from Mr M. T. Manjunath and Mr Mohammed Mushtaq (State Load Dispatch Centre, Karnataka).

Received 5 July 2019; revised accepted 22 July 2019

doi: $10.18520 / \mathrm{cs} / \mathrm{v} 117 / \mathrm{i} 8 / 1347-1353$ 